\title{
(2) OPEN ACCESS \\ Covert medication and patient identity: placing the ethical analysis in a worldwide context
}

\author{
Neil John Pickering ()
}

Correspondence to

Associate Professor Neil John

Pickering, Bioethics Centre,

University of Otago Dunedin

School of Medicine, Dunedin, New Zealand;

neil.pickering@otago.ac.nz

Received 13 July 2020

Revised 27 October 2020

Accepted 30 October 2020

\section{ABSTRACT}

In a recent JME article, Guidry-Grimes, Dean and Victor offer some signal and challenging insights into the ethical analysis of covert medication (in general) and in particular when administered via food. They warn of impacts on identity likely to emerge from using food in this way. In particular, they caution against allowing families to be involved in covert medication, in the light of their central role in sustaining identity. Their analysis has particular purchase in resource rich contexts and those contexts where individual identity is a central concern. But it is less clear that the article's insights are relevant to other contexts. This article places the analysis of covert medication and identity in a wider context, arguing both that the focus on identity is equally significant when analysing potential alternatives to covert medication, such as coercion; and that the ethical analysis of covert medication offered by Guidry-Grimes, Dean and Victor lacks global applicability. It seems to lack application particularly in resource-poor contexts, and in cultures where identity and community are interconstituted.

\section{INTRODUCTION}

Covert administration of medication (CM) is an issue in many parts of the world, and everywhere the ethical quandaries it presents are recognised. But the ethical assessment of CM is not always the same everywhere. There is then a case for placing insights into the ethical analysis of CM in the widest possible context. This includes placing them within a wider framework of ethical analysis and within the worldwide practice of $\mathrm{CM}$.

A recent article published in the JME gives us important insights into $\mathrm{CM}$, particularly when it is administered through food and drink. But the ethical insight and advice contained in the article need to be analysed within a wider ethical framework and within a worldwide context. It will be argued here that in this wider ethical and world context, some questions arise about the ethical implications claimed in the article.

\section{Check for updates}

(c) Author(s) (or their employer(s)) 2020. Re-use permitted under CC BY-NC. No commercial re-use. See rights and permissions. Published by BMJ.

\begin{tabular}{|l|}
\hline To cite: Pickering NJ. \\
J Med Ethics Epub ahead of \\
print: [please include Day \\
Month Year]. doi:10.1136/ \\
medethics-2020-106695 \\
\hline
\end{tabular}

\section{COVERT MEDICATION IN FOOD-THE MORAL GAMBLE}

In their article on what they refer to as the moral gamble of CM, Guidry-Grimes, Dean and Victor make a significant central point. CM administered via food or drink strikes at the goods that eating and drinking represent and give in a person's life.

Food and eating practices are sources of health, opportunities to exercise autonomy, ways to create valuable experiences (eg, pleasure, cultural connections), ways to express/reinforce identity and ways of reinforcing/building connections with others. Eating is also a relational practice, one that entails significant vulnerability to and dependency on others. ${ }^{1}$

Placing relationships at the moral hub of their analysis they aim to 'give an analysis of the ways that these relationships can be undermined and trust eroded through using food for the covert administration of medication'. ${ }^{1}$

The analysis adds to ethical reasons for hesitating to use CM, at least when food and drink are the vehicle. In particular it adds a new and subtle dimension to the existing analysis. In the existing literature, much of the focus on $\mathrm{CM}$ via food and drink has been on the concrete dangers of administering medicines which have had their standard form and/or mode of administration altered. For example there are concerns related to the action of pills that have been crushed or of powder that has been taken out of capsules; and concerns about how much medication is actually taken in food if the person does not eat everything. ${ }^{2}$ But the relational elements and the meanings and symbolism of shared eating have not typically been a major focus previously.

In addition, the paper shows how ethical problems may build up over time and provides a strong argument for constant review.

\section{We contend that while there may be instances in which using food for covert medication is ethically justified, given a lack of suitable alternatives, in any given case this practice should be continually re- evaluated in light of the building moral costs to the relational agent over time. ${ }^{1}$}

Here, I aim to place Guidry-Grimes, Dean and Victor's paper, within a wider context, and in particular within the wider moral framework in which the use of CM (including CM given via food and drink) may be analysed, and within the wider cross-cultural context of the practice of CM.

\section{AN ETHICAL FRAMEWORK FOR ANALYSIS OF CM}

The wider framework for the analysis of CM accepted by Guidry-Grimes, Dean and Victor is in itself relatively uncontroversial, being either very well supported in the literature or more or less self-evident. First, CM should be considered only when the person is judged unable to make their own health decisions (call this the incompetence condition). ${ }^{2-8}$ Second, CM is acceptable only when it is done in line with best practice for the covert mode of administration (call this the best practice condition-this condition is not much discussed, 
but seems relatively self-evident). Third, CM is acceptable only when it is the best option available in the circumstances (call this the best option condition). ${ }^{34-13}$ That the authors adhere to the best option condition, we can imply from two things GuidryGrimes, Dean and Victor say. First, they say (as in the quotation above) that CM may be an ethical choice when the alternatives are worse. Such alternatives include continued decompensation (that is to say a worsening of the person's symptoms) or coercive or even forceful administration of medication. Second, they say CM may be morally acceptable when the circumstances are such that it supports the very things (such as identity) which (under some other circumstances) it undermines. In short, they acknowledge that there are cases where CM is indeed the best option, though perhaps of a rather unappetising menu.

\section{IDENTITY AND CM AS THE BEST OPTION IN THE CIRCUMSTANCES}

In relation to its impact on identity in particular, any full analysis of whether CM is the best option or not needs to consider two possibilities. First, whether CM is necessarily inimical to identity preservation and enhancement in a specific case; and second, whether alternatives, such as coercion or allowing the patient's illness to worsen, are equally bad or worse for identity.

Guidry-Grimes, Dean and Victor acknowledge that there are cases where CM may support identity. They cite the work of Lindemann. ${ }^{14}$ If identity is supported by activities such as those which take place at meal times (and other gatherings), and if a person's unmedicated behaviours make attendance at such social gatherings difficult or impossible, and if CM is in fact the best means of supporting such attendance, then there seems to be a prima facie case for its use.

Putting aside whether CM is capable of supporting identity in any particular instance, it may be the case that none of the alternatives will do any better. For example, the use of threats (coercion) seems as likely as CM to sour and colour a relationship. If identity relies to some degree on trusting relationships, as Guidry-Grimes, Dean and Victor suggest it does, and yet threats and pressures are part of those relationships, then coercion is as likely to undermine identity as is CM.

There is in addition empirical evidence that patients feel their identity is very much at stake in coercive treatment. In a study in Norway in 2016, Norvoll and Pedersen noted a number of ways in which patients found coercion impinged on their identity. ${ }^{15}$ At the extreme, participants experienced the existential impact of coercion, which the authors describe as 'an all embracing dehumanisation, depersonalisation or loss of self, which was reflected in their [the participants'] reactions to being committed: 'See me, I am disappearing, I am about to disintegrate". ${ }^{15}$

In addition, in this study, the participants identified impacts of their own untreated or uncontrolled illnesses on their identity, in particular on their self-expression, which is described as 'inner coercion'. Summarising the authors report that

\begin{abstract}
Descriptions of inner coercion or limitations were related to participant's mental health problems, problems with selfexpression, or weak will resulting from substance abuse, which increased feelings of powerlessness and being unfree, while stimulating a strong urge to be able to and be given the possibility to express themselves and to be understood. ${ }^{15}$ (p207)
\end{abstract}

Ironically, patients looking for a way out of this 'inner coercion' often found that external coercion compounded their sense of being deprived of self-expression and the hope of being understood.
This is not to say that there are not potentially ethically significant differences between the impacts on identity of coercion and of CM. Coercion is experienced by the person, whereas CM-in so far as it can be kept a secret-is not. This implies a fundamental conundrum in the use of CM, in that even if it aims to support identity, it does so by threatening it, at least in so far as identity is based on knowledge about one self (including whether one is being medicated or not). This conundrum is absent in coercive treatment. ${ }^{16}$

In addition, in coercive treatment, a person can be given some measure of procedural justice. In this, a person is kept informed about what is happening and is going to happen to them, and even if this is not what they want, there is evidence that it reduces the experience of coercion. ${ }^{17}$ But in CM this is not possible-the very knowledge that would be needed to give procedural justice is denied the patient.

However, the ethical differences between coercive treatment and CM should not be overemphasised. A fear Guidry-Grimes, Dean and Victor express is that CM, once discovered by a patient, might colour all future experience. The person might always wonder if they can trust their perceptions and relationships again. However, in support of this fear relating to CM, GuidryGrimes, Dean and Victor cite a finding about the impact of coercive treatment: 'Involuntary or forced psychiatric treatment 'can give the perception of an isolated event', but 'the moral weight of the act is ongoing throughout the relationship". ${ }^{1}$ (citing ${ }^{18} 18$ )

This suggests that even isolated instances of coercion may remain with a patient, having a long-lasting impact on the relationship in question, and (one might surmise) on subsequent relationships.

In short, when CM is compared with alternatives, in relation to the issues of identity and trust raised by Guidry-Grimes, Dean and Victor, it does not necessarily come out worse.

\section{THE ROLE OF FAMILIES IN CM AND THE MATERIAL CONTEXT}

The final ethical call of the article is that families should not, except in the most extreme cases, be involved in CM. This may seem a straightforward call, but in a global context it is arguably the most questionable of the article. The case for this will be made in this section and the next on Identity and culture.

The authors say:

Finally, we want to call attention to the moral danger of having loved ones-partners, family or friends-participate directly in covert administration of medication. Though certain extreme cases might necessitate their involvement due to a lack of acceptable alternatives, this option should be a last resort. ${ }^{1}$

The basis of this call is clear enough from the article. A person's loved ones are often the anchor for the relational aspects of identity, and the basis of their social support. For example, in a case described by Guidry-Grimes, Dean and Victor, the patient, $\mathrm{Mr}$ Jones is in the care of his sister, who has been giving him medication in his food. It seems to be Guidry-Grimes, Dean and Victor's view that while the moral risks of CM via food delivered in institutional settings may be reduced, because the professionals at the institution are not so closely associated with a patient's identity, they are greatly increased when those responsible for the deception are those closest to the person and the most trusted.

However, the ethical basis of this call seems to render questionable a very large swathe of practice worldwide, which material circumstances seem potentially to validate. Guidry-Grimes, Dean and Victor rightly mention that their analysis may have 
limited purchase where professional healthcare is difficult to access. Rightly, they mention India as a possible example, and refer to inaccessibility of professional care there. Though India has had a National Mental Health Programme (NMHP) since the early $1980 \mathrm{~s},{ }^{19}$ the accessibility of professional help remains severely limited.

What Guidry-Grimes, Dean and Victor perhaps under explore is the sheer scale of the problem in a country such as India. According to a report on the burden of mental disorders in India's states, 'in 2017, there were 197.3 million (95\% UI 178.5-216.4) people with mental disorders in India, comprising $14.3 \%$ of the total population of the country'. ${ }^{20}$ Expenditure on health was $5 \%-6 \%$ of GDP, but only $1 \%-2 \%$ of this was on mental health (ie, around $0.1 \%$ of GDP). ${ }^{21}$ This level of spending was reflected in figures relating to availability of psychiatric beds. The number of beds in psychiatric hospitals per 10000 patients was 1.490, and in general hospitals it was $0.823 .{ }^{21}$ In India there were two mental health workers and 0.3 psychiatrists per 100000 population, which is much lower than the global average. ${ }^{20}$ There were only 43 government-funded mental health hospitals. ${ }^{22}$

This challenge was recognised in the NMHP, which sought inter alia to make community mental health provision more available. However, as Murthy reported in 2004, the NMHP is widely regarded as having failed to deliver the level of community mental health provision hoped for and required: 'Currently, most districts do not have trained professionals or the mental health infrastructure to provide essential mental healthcare. ${ }^{23}$ (p83) Recognising this comparative absence of community mental health services, when the NMHP was reviewed (starting in May 2001) subsequent recommendations included a number of revised Goals among which were 'Strengthening families and communities for the care of persons suffering from mental disorders'. ${ }^{23}$ (p82)

Kala writing specifically on the use of CM also notes that there is little community mental health infrastructure. ${ }^{24} \mathrm{He}$ links this lack to the role of the family. He draws the conclusion that:

for decades to come the only community mental health teams that we are going to have are the families and as has been suggested here, we should look for ways to empower them and allot them a role in a due process of OPD medication (without consent). ${ }^{24}$ See also Ref 25.

If $\mathrm{CM}$ is going to be used in material circumstances like these, even only as a last resort, the vast majority of it would need to be accomplished through the families. The suggestion that these families are a source of or are in moral danger is to say the least unhelpful, given the realities of their material circumstances. The sheer scale of the problem seems to undermine the ethical force of the authors' call.

If the angle of vision of the moral analysis is narrowed to resource-rich countries where accessibility is much less of a problem this judgement about family involvement may cut ice. But it is difficult to see what force this claim should have where inaccessibility of professional help is the rule for large parts of the population.

\section{IDENTITY AND CULTURE}

In the last section, it was argued that the material realities of the context within which CM may be considered can raise a question over Guidry-Grimes, Dean and Victor's call that families should not be involved.

In this section, a distinct though related point will be made. Guidry-Grimes, Dean and Victor focus their analysis around the impact of CM on identity. However, the notion of identity and of the individual may also be culturally and materially influenced. While Guidry-Grimes, Dean and Victor appeal to a relational notion of identity, their focus is still very much on the individual, and the preservation of individual identity. But identity and individuality may be very differently understood and experienced in diverse cultural contexts. The moral hazards of CM seem to be magnified where ethical concerns bottom out with the individual. But where individuality and identity is understood and experienced not just as the product of relationships, but also in terms of role, responsibilities to family and community, then the ethical analysis of CM may appear in rather different terms.

There is a danger in offering this analysis of over-stating cultural differences and relativising ethics to culture, which can and should be avoided. ${ }^{26}{ }^{27}$ Nonetheless, cultural differences should not be ignored.

Suffice it to say that Indian society cannot be seen other than in familial and communal terms. It is and has been for centuries a family-oriented and community-based society. In an Indian family life, one's individuality is subordinated to collective solidarity, and one's ego is submerged into the collective ego of the family and one's community. Consequently when a problem-financial, medical, psychiatric, or whatever-affects an individual, it affects the entire family. ${ }^{28}$ See also Ref. $^{29}$

This is a widely accepted account of Indian society, one term used to describe it being 'collectivist'.

'Collectivism' refers to the philosophic, economic or social outlook that emphasises the interdependence among human beings. It is the basic cultural element for cohesion within social groups, which stresses on the priority of group goals over individual goals in contrast to 'individualism', which emphasises on what makes the individual distinct, and promotes engagement in competitive tasks. ${ }^{30}$

The family has been described as the prototypical collectivist relationship. ${ }^{31}$ (p156) The family is at once shaped by collectivism and is the instrument by which collectivist values are passed on and learnt. The question is whether CM would be experienced as the assault on the self, which seems to be described in Guidry-Grimes, Dean and Victor's article, in the context of a society where the individual, the community and the family are experienced as strongly interconstitutive.

There are several subtly intertwined aspects to this issue. First, it may be the view of some communal societies that the sort of self-knowledge leading to full control over one's own destiny is not necessarily the most highly valued feature of a person's moral constitution. Rather, as in cases described in Wong, Poon and Hui and Khurshid a good life may be understood in terms of the person's being part of his or her own family, providing for the family, and so on. ${ }^{10} 32$ The values which relate the self to the family within the Indian context have been described as 'belongingness, dependency, empathy, and reciprocity' while the values which would be more familiar in a Western context such as 'personal autonomy, space and privacy', while not necessarily entirely unimportant, are secondary. ${ }^{30}$ The good individual in a family within a collectivist milieu is foremost one who fulfils their role or roles. In this light, CM which enables a person to fulfil these roles may be seen as a means to the person fulfilling themselves which they might otherwise not be able to do.

Second, parallel to this, it may be felt that where there are conflicts it is the centrality and rights of the family and the concomitant duty of the individuals that should be emphasised 
In the case of individualism, the organizing theme is the centrality of the autonomous individual; in the case of collectivism, it is the centrality of the collective-family, tribe, work organization, consumer group, state, ethnic group, or religious group. ${ }^{31}$ (p156)

Wong, Poon and Hui arguing from a Chinese (rather than Indian perspective) say:

There should ... be a weighing of family rights against individual rights. In Chinese culture, the notion of respect for an individual's right to self determination is a weak notion due to the Confucian concept of social personhood. ...

A justification for continuing treatment of the patient with covert medication can be found in society's moral obligation to protect family interests and to preserve family autonomy. If the patient belongs to a family, then the interests of each member of the family are interconnected, and there should be mutual respect for each other's autonomy. ${ }^{10}$

We may take this analysis one step further, and suggest that an individual embedded in the collectivist family milieu may not see $\mathrm{CM}$ as morally objectionable, even where he or she is the recipient. Honkanen rightly reflects that CM may in some contexts be in line with the 'cultural fibers, belief system' of the patient. ${ }^{5}$ In collectivist cultures, and Indian culture specifically, individuals have been shown to perceive the most pressing moral demands on them as arising where there is dependence and need. ${ }^{33}$ (p44) An individual may see CM as justified where it enables his or her family to meet these pressing moral demands. Further, patients may recognise that being medicated covertly is the right thing for the family to do for them. That is to say, from a moral perspective, the patient who receives CM may see it as justified.

The wider point to be made from this is that the moral analysis of CM should reflect how the individual may regard CM, and not assume that it will be seen as an affront. The narrower point is that in important contexts around the world, where CM may be practised and be a matter of ethical debate, the analysis offered by Guidry-Grimes, Dean and Victor appears parochial.

\section{CONCLUSION}

Guidry-Grimes, Dean and Victor's insights are signal and challenging to practice, particularly in resource-rich contexts. However, placing their insights into a wider ethical and cultural context raises some questions about the application of their analysis and the scope of their conclusions.

\section{Contributors I am sole author.}

Funding The authors have not declared a specific grant for this research from any funding agency in the public, commercial or not-for-profit sectors.

\section{Competing interests None declared.}

Patient consent for publication Not required.

Provenance and peer review Not commissioned; externally peer reviewed.

Data availability statement There are no data in this work.

Open access This is an open access article distributed in accordance with the Creative Commons Attribution Non Commercial (CC BY-NC 4.0) license, which permits others to distribute, remix, adapt, build upon this work non-commercially, and license their derivative works on different terms, provided the original work is properly cited, appropriate credit is given, any changes made indicated, and the use is non-commercial. See: http://creativecommons.org/licenses/by-nc/4.0/.

\section{ORCID iD}

Neil John Pickering http://orcid.org/0000-0001-8629-1627

\section{REFERENCES}

1 Guidry-Grimes L, Dean M, Victor EK. Covert administration of medication in food: a worthwhile moral gamble? J Med Ethics 2020;0:1-5.

2 Muramatsu RS, Litzinger MHJ, Fisher E, et al. Alternative formulations, delivery methods, and administration options for psychotropic medications in elderly patients with behavioral and psychological symptoms of dementia. Am J Geriatr Pharmacother 2010;8(2):98-114.

3 Welsh S, Deahl M. Covert medication - ever ethically justifiable? Psychiatr Bull 2002;26(4):123-6.

4 Whitty P, Devitt P. Surreptitious prescribing in psychiatric practice. Psychiatr Serv 2005:56(4):481-3.

5 Honkanen L. Point-Counterpoint: is it ethical to give drugs covertly to people with dementia? NO: covert medication is paternalistic. West J Med 2001;174(4):229.

6 College statement on covert administration of medicines. Psychiatric Bulletin 2004;28(10):385-6.

7 Stroup S, Swartz M, Appelbaum P. Concealed medicines for people with schizophrenia: a U.S. perspective. Schizophr Bull 2002;28(3):537-42.

8 Barreto S. Covert administration of medications in old age psychiatry: a reflection. JGCR 2017:4:28-31.

9 Haw C, Stubbs J. Covert administration of medication to older adults: a review of the literature and published studies. J Psychiatr Ment Health Nurs 2010;17(9):761-8

10 Wong JGWS, Poon Y, Hui EC. "I can put the medicine in his soup, Doctor! ". J Med Ethics 2005;31(5):262-5.

11 Lamnari AM. Point-Counterpoint: is it ethical to give drugs covertly to people with dementia? YES: it is ethical if it is in their best interests. West J Med 2001;174(4):228.

12 Hung EK, McNiel DE, Binder RL. Covert medication in psychiatric emergencies: is it ever ethically permissible? J Am Acad Psychiatry Law 2012;40(2):239-45.

13 Ramsay $S$. UK nurses receive guidance on covert medication of patients. Lancet 2001;358(9285):900.

14 Lindemann $\mathrm{H}$. Holding one another (well, wrongly, clumsily) in a time of dementia. Metaphilosophy 2009;40(3-4):416-24.

15 Norvoll R, Pedersen R. Exploring the views of people with mental health problems' on the concept of coercion: towards a broader socio-ethical perspective. Soc Sci Med 2016;156:204-11.

16 Ahern L, Van Tosh L. The irreversible damage caused by surreptitious prescribing. Psychiatr Serv 2005;56(4):383.

17 Lidz CW, Hoge SK, Gardner W, et al. Perceived coercion in mental hospital admission. pressures and process. Arch Gen Psychiatry 1995:52(12):1034-9.

18 Olsen DP. Influence and coercion: relational and rights-based ethical approaches to forced psychiatric treatment. J Psychiatr Ment Health Nurs 2003;10(6):705-12.

19 National Institute of Mental Health and Neuro Sciences Bengaluru \& partner institutions. National mental health survey of India, 2015-16. National Institute of Mental Health and Neuro Sciences, 2016.

20 India State-Level Disease Burden Initiative Mental Disorders Collaborators. The burden of mental disorders across the states of India: the global burden of disease study 1990-2017. Lancet Psychiatry 2020;7(2):148-61.

21 Bagcchi S. Rethinking India's psychiatric care. Lancet Psychiatry 2014:503-4.

22 Department of Mental Health and Substance Abuse, World Health Organization. Mental health atlas 2011. WHO, 2015.

23 Murthy RS. The National Mental Health Programme: Progress and Problems. In: Agarwal SP, ed. Ministry of health and family welfare: Directorate General of health services, 2004: 75-91.

24 Kala AK. Covert medication; the last option: a case for taking it out of the closet and using it selectively. Indian J Psychiatry 2012;54(3):257-65.

25 Kapur RL. The Story of Community Mental Health in India. In: Agarwal SP, ed. Ministry of health and family welfare: Directorate General of health services, 2004: 92-100.

26 Pickering N. Covert treatment in a cross-cultural setting. In International Perspectives in Values-Based Mental Health Practice - Case Studies and Commentaries: Drozdstoy Stoyanov D, Fulford B, Stanghellini G, et a/Dordrecht: Springer, In press.

27 Nie J-B, Fitzgerald RP. Connecting the East and the West, the local and the universal: the methodological elements of a transcultural approach to bioethics. Kennedy Inst Ethics J 2016;26(3):219-47.

28 Laungani P. Mental illness in India and Britain: theory and practice. Med Law 1997;16(3):509-40.

29 Laungani P, Adler LL, Gielen UP. The influence of culture on stress: India and England. In Cross-Cultural topics in psychology: Adler LL, Gielen UPWestport, CT: Praeger, 2001: 149-69.

30 Chadda RK, Deb KS. Indian family systems, collectivistic Society and psychotherapy. Indian J Psychiatry 2013;55(Suppl 2):299-309.

31 Triandis HC. Collectivism and individualism as cultural syndromes. Cross-Cultural Research 1993;27(3-4):155-80.

32 Khurshid KA. A tale of two cities. American Journal of Psychiatry 2006;163(8):1335-6.

33 Miller JG, Bersoff DM, Harwood RL. Perceptions of social responsibilities in India and in the United States: moral imperatives or personal decisions? J Pers Soc Psychol 1990;58(1):33-47. 